\title{
THE PHARMACOKINETICS OF NEOSTIGMINE AND 3-HYDROXYPHENYLTRIMETHYL- AMMONIUM IN THE RAT: DOSE-DEPENDENT EFFECTS AFTER PORTAL VEIN ADMINISTRATION
}

\author{
H.E. BARBER \& G.R. BOURNE \\ Department of Pharmacology \& General Therapeutics, University of Liverpool
}

1 The elimination kinetics of $\left[{ }^{14} \mathrm{C}\right]$-neostigmine iodide and $\left[{ }^{14} \mathrm{C}\right]-3$-hydroxyphenyltrimethylammonium iodide (3-OH PTMA) have been studied in the rat.

2 The presence of a renal secretory pathway for neostigmine and 3-OH PTMA has been confirmed.

3 For neostigmine and 3-OH PTMA, at a given dose level, the fraction of the dose eliminated unchanged was reduced and the metabolite fraction was increased after portal vein administration when compared to jugular vein administration. This indicates that both compounds are subject to extensive metabolism during the first passage through the liver.

4 Neostigmine was eliminated by dose-independent kinetics after jugular vein administration but dose-dependent after portal vein administration. In the latter case the fraction eliminated as neostigmine increased with increasing dose. This increase was not accompanied by any change in the fraction of the metabolites eliminated.

5 After portal vein administration of 3-OH PTMA, the fraction of the dose eliminated as 3-OH PTMA also increased with increasing dose. This change was accompanied by a decrease in the fraction of the metabolites eliminated which were excreted at a constant rate.

\section{Introduction}

It is often assumed that drugs are eliminated by first order processes and a consequence of this is that the 'biological half life' and composition of excretion products are independent of dose. However, it is now apparent that the elimination of some drugs is not by first order processes but is dose-dependent. Deviations from apparent first order drug elimination kinetics may be detected by changes in the fractional composition of the excretion products with dose, if renal clearance is constant and not affected by changes in urine flow or pH (Levy, 1968).

Previous pharmacokinetic studies have shown that neostigmine iodide, a quaternary nitrogen compound, is metabolized in the liver in the rat and excreted by renal tubular secretion in the rat and hen (Roberts, Thomas \& Wilson, 1965a and b). The principal metabolite has been identified as 3-hydroxy phenyltrimethylammonium iodide (3-OH PTMA) which is further metabolized to a glucuronide and several minor metabolites (Husain, Roberts, Thomas \& Wilson, 1969; Somani, Roberts, Thomas \& Wilson, 1970). Biliary excretion has been shown to be a minor route of elimination of neostigmine and its metabolites (Calvey, 1966; Somani, Wright \& Calvey, 1970).
This report describes further studies of the pharmacokinetics of neostigmine and 3-OH PTMA. The purpose of the investigation was to determine if the elimination kinetics of neostigmine and 3-OH PTMA may be described by first order processes or are capacity limited. The renal clearance of neostigmine and 3-OH PTMA and its metabolites have been determined during constant infusion. The effect of dose and route of administration on the fraction composition of urine has been studied after rapid intravenous injection of single doses of neostigmine and 3-OH PTMA. The 'biological half life' of neostigmine and 3-OH PTMA has been determined from plasma concentration-time curves and urinary excretion data.

\section{Methods}

\section{Experimental procedure}

Male Wistar rats (body weight: $250-350 \mathrm{~g}$ ) were anaesthetized by an intraperitoneal injection of ethyl carbamate $(1.4 \mathrm{~g} / \mathrm{kg}$ as a $14 \%$ solution in distilled water). A tracheotomy was performed. 
The jugular vein and both ureters were cannulated with polyethylene tubing (Portex pp50). A 6\% solution of mannitol in $0.9 \% \mathrm{w} / \mathrm{v} \mathrm{NaCl}$ solution (saline) was constantly infused via the jugular vein at a rate of $0.075 \mathrm{ml} / \mathrm{min}$ to maintain a constant diuresis.

In some experiments the carotid artery was cannulated and in these cases heparin (125 i.u./100 g) was administered intravenously. In other experiments a 22 gauge needle attached to a length of fine polyethylene tubing (Portex pp10) was inserted into the portal vein near the hilum of the liver. The other end of the polyethylene tubing was attached to a needle and syringe from which drugs were ad ministered.

\section{Renal clearance studies}

$\left[{ }^{3} \mathrm{H}\right]$-inulin $(5 \mu \mathrm{Ci}$; specific activity $60 \mu \mathrm{Ci} / \mathrm{mg})$ and $\left[{ }^{14} \mathrm{C}\right]$-neostigmine iodide $(0.4,0.58$ or $0.96 \mu \mathrm{mol}$; specific activity $5.2 \mathrm{mCi} / \mathrm{mM}$ ) or [ $\left.{ }^{14} \mathrm{C}\right]-3-\mathrm{OH}$ PTMA (specific activity $10.2 \mathrm{mCi} / \mathrm{mmol}, 0.3$ or $0.6 \mu \mathrm{mol}$ alone or after a priming dose: $0.3 \mu \mathrm{mol}$ ) each labelled with ${ }^{14} \mathrm{C}$ in one of the methyl groups of the quaternary nitrogen were included in the infusion mixture. A priming dose of neostigmine was not given because of the gross pharmacological effects if too much is rapidly administered. A stabilization period of 10-15 min was allowed then six, seven or ten clearances were measured over periods of 10 minutes. Urine flow rate was calculated from the volume of urine measured by weight, assuming unit density. Blood $(0.1-0.2 \mathrm{ml})$ was collected from the carotid artery at the midpoint of the urine collection period. The plasma was separated by centrifugation. Samples of plasma snd urine were assayed for inulin and the drug under study as described below.

\section{Pharmacokinetic studies}

$\left[{ }^{14} \mathrm{C}\right]$-neostigmine iodide (dose: $0.35,0.74$ or $1.5 \mu \mathrm{mol} / \mathrm{kg}$ ) was administered by rapid intravenous injection via the jugular or portal vein. After administration of neostigmine via the jugular vein (dose: 0.74 or $1.5 \mu \mathrm{mol} / \mathrm{kg}$ ) urine was collected in 10 min intervals for up to 80 minutes. During a single experiment at the lower of these two dose levels and each experiment at the higher dose level, blood samples (0.1-0.2 ml) were collected from the carotid artery at the midpoint of each urine collection period. Following administration of neostigmine iodide $(0.35 \mu \mathrm{mol} / \mathrm{kg})$ via the jugular vein and during all experiments following portal vein administration, samples of urine were collected in 5 min periods for the first $20 \mathrm{~min}$ then for six $10 \mathrm{~min}$ collection periods. In some experiments arterial blood pressure was monitored from the femoral artery. No change in this parameter was noted after administration of neostigmine via the portal vein. However, when the drug was given via the jugular vein the arterial blood pressure fell between 10 and $40 \mathrm{mmHg}$ (depending on dose), this fall lasting up to 10 minutes.

$\left[{ }^{14} \mathrm{C}\right]-3-O H$ PTMA iodide was also administered by rapid intravenous injection via the jugular vein (dose: $1.96 \mu \mathrm{mol} / \mathrm{kg}$ ) or via the portal vein (dose: 0.34 or $1.96 \mu \mathrm{mol} / \mathrm{kg}$ ). Urine was collected in 5 , 10 or 20 min periods for up to 90 minutes. After administration via the jugular vein, samples of blood $(0.1-0.2 \mathrm{ml})$ were collected from the carotid artery at the midpoint of the urine collection period.

Plasma was separated by centifugation and urine volume was determined by weight.

\section{Liquid scintillation counting and assay procedures}

Plasma and urine $(0.05 \mathrm{ml})$ were assayed for $\left[{ }^{3} \mathrm{H}\right]$-inulin and total ${ }^{14} \mathrm{C}$ following renal clearance studies and for total ${ }^{14} \mathrm{C}$ following pharmacokinetic studies by liquid scintillation counting, using $10 \mathrm{ml}$ of a homogeneous Triton X-100 scintillant $(666.6 \mathrm{ml}$ toluene, $333.3 \mathrm{ml}$ Triton $\mathrm{X}-100,75 \mathrm{ml}$ water and $6 \mathrm{~g}$ butyl P.B.D. ( 2(4 ${ }^{1}$ - $t$-butylphenyl)-5(4"biphenylyl) $1,3,4$,oxadiazole)), (Barber \& Bourne, 1973). All samples were counted in a Nuclear Chicago Unilux II scintillation spectrometer with Ba-133 external source. Quench correction was by the channels ratio or external standard channels ratio method.

Samples of plasma and urine were extracted for $\left[{ }^{14} \mathrm{C}\right]$-neostigmine by the liquid cation exchange procedure previously described (Barber, Bourne \& Buckley, 1972): $\mathrm{NaOH}(0.05 \mathrm{ml})$ and ethyl butyl ketone $(0.1 \mathrm{ml})$ containing sodium tetraphenyl boron ( $\mathrm{Na}$ TPB, $20 \mathrm{mg} / \mathrm{ml}$ ) was added and extraction effected by shaking using a vortex mixer. After centrifugation the upper organic phase was removed and the radioactivity due to neostigmine assayed by liquid scintillation spectrometry. The concentration of the total metabolites of neostigmine was determined by difference between total ${ }^{14} \mathrm{C}$ and neostigmine.

After administration of 3-OH PTMA this compound was separated from its metabolite in plasma and urine by the liquid cation exchange procedure without the addition of $\mathrm{NaOH}$. This procedure extracts only 3-OH PTMA as shown by the following: samples of urine containing $\left[{ }^{14} \mathrm{C}\right]-3-O H$ PTMA iodide and its metabolites were subjected to paper electrophoresis in barbitone buffer, pH 6.9, as previously described (Husain et al., 1969). The electrophoretograms were scanned 
for radioactivity (Radiochromatogram Scanner, Tracer Lab Ltd, England) and those peaks corresponding to the metabolites of 3-OH PTMA were cut from the chromatogram and eluted with warm distilled water. All eluates were collected and the total volume reduced by evaporation at room temperature under reduced pressure. Further electrophoresis confirmed the purity of the product and the radioactivity present was determined by scintillation counting. Samples of authentic 3-OH PTMA and the prepared metabolite were mixed in known proportions and extractions effected as described. The results in Table 1 confirm that 3-OH PTMA only is extracted by NaTPB. The amount of metabolites present was determined by difference between total ${ }^{14} \mathrm{C}$ and parent drug extracted.

\section{Results}

\section{Renal clearance studies}

(a) Neostigmine. The clearance of inulin $\left(\mathrm{C}_{\text {In }}\right)$ and neostigmine $\left(\mathrm{C}_{\mathrm{Neo}}\right)$ and the plasma level of neostigmine were determined for all collection periods. Four groups of clearance values were obtained for the following neostigmine plasma levels: $\quad 0.03-0.04,0.05-0.06, \quad 0.06-0.08$, and 1.5-2.0 $\mu$ molar. The mean urine flow rate $\left(C_{\text {In }}\right)$, plasma level of neostigmine and the neostigmine to inulin clearance ratio for each group are shown in Table 2. The clearance of inulin and the urine flow rate were reduced at the highest plasma level of neostigmine. The $\left(\mathrm{C}_{\mathrm{Neo}}\right)$ was always greater than that of inulin. Compounds which are secreted by renal tubular mechanisms have a clearance greater than that of inulin (Smith, 1956) thus these results confirm the previous report of Roberts et al. (1965a) that neostigmine is secreted by renal tubular mechanisms in the hen. Over the range of plasma levels studied, the clearance ratio was independent of the plasma level. The capacity of the secretory pathway was not exceeded as the clearance ratio $\left(\mathrm{C}_{\mathrm{Neo}} / \mathrm{C}_{\mathrm{In}}\right)$ did not approach 1 at the highest plasma level.

(b) 3-Hydroxyphenyltrimethylammonium. For all collection periods the $\left(\mathrm{C}_{\mathrm{In}}\right)$, clearance of 3-OH PTMA ( $\left.\mathrm{C}_{3-\mathrm{OH} \text { PTMA }}\right)$ and the plasma level of

Table 1 Extraction of $\left[{ }^{14} \mathrm{C}\right]-3$-hydroxyphenyltrimethylammonium (3-OH PTMA) from mixed sample of 3-OH PTMA and its metabolites

Theoretical ratio (\%)

Total

$d / \min$

3500

570

1500

\section{3-OH PTMA}

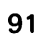

43

14

Metab
9
57
86

\section{Calculated ratio}

$\begin{array}{cc}\text { 3.OH PTMA } & \text { Metab. } \\ \text { (organic phase) } & \text { (residue) }\end{array}$

91

$40 \quad 60$

All results are mean of triplicate determinations.

Table 2 The clearance ratio of $\left[{ }^{14} \mathrm{C}\right]$-neostigmine iodide to inulin at various plasma concentrations of neostigmine

$\begin{array}{cccc}\begin{array}{c}\left(C_{l n}\right) \\ \left(\mathrm{m} / \mathrm{min}^{-1} 100 \mathrm{~g}^{-1}\right)\end{array} & \begin{array}{c}\text { Urine flow } \\ (\mathrm{m} / / \mathrm{min})\end{array} & \begin{array}{c}\text { Plasma conc. } \\ \text { neostigmine } \\ (\mu \text { molar) }\end{array} & C_{\mathrm{Neo}} / C_{/ n} \\ 0.461 \pm 0.057 & 0.030 \pm 0.002 & 0.38 \pm 0.05 & 2.62 \pm 0.29 \\ 0.478 \pm 0.040 & 0.041 \pm 0.005 & 0.55 \pm 0.02 & 2.61 \pm 0.33 \\ 0.565 \pm 0.056 & 0.043 \pm 0.004 & 0.72 \pm 0.03 & 2.44 \pm 0.28 \\ 0.211 \pm 0.032 & 0.022 \pm 0.002 & 1.67 \pm 0.08 & 3.42 \pm 0.35 *\end{array}$

$C_{1 n}=$ clearance of inulin.

Results are mean with s.e. of six determinations.

* No significant difference $(P>0.05)$ between the clearance ratio at the highest plasma level of neostigmine and at each other plasma level. Statistical analysis was by Student's $t$-test and a non-parametric method (Quenouille, 1959). 
Table 3 The clearance ratio of $\left[{ }^{14} \mathrm{C}\right]-3$-hydroxyphenyltrimethylammonium iodide (3-OH PTMA) to inulin at various plasma concentrations

$\begin{array}{cc}\begin{array}{c}\text { Clearance of } \\ \text { inulin } \\ \left(\mathrm{m} / \mathrm{min}^{-1} 100 \mathrm{~g}^{-1}\right)\end{array} & \begin{array}{c}\text { Urine flow } \\ (\mathrm{m} / \mathrm{min})\end{array} \\ 0.523 \pm 0.032 & 0.040 \pm 0.002 \\ 0.532 \pm 0.044 & 0.040 \pm 0.002 \\ 0.612 \pm 0.024 & 0.042 \pm 0.001 \\ 0.476 \pm 0.047 & 0.037 \pm 0.002 \\ 0.315 \pm 0.027 & 0.032 \pm 0.002 \\ 0.275 \pm 0.025 & 0.029 \pm 0.001\end{array}$

\begin{tabular}{|c|c|}
\hline $\begin{array}{c}\text { Plasma } \\
\text { conc. } \\
\text { 3-OH PTMA } \\
\text { (umolar) }\end{array}$ & $\begin{array}{c}{\left[{ }^{14} \mathrm{C}\right]-3-O H \text { PTMA/ }} \\
C_{/ n}\end{array}$ \\
\hline $0.167 \pm 0.006$ & $3.59 \pm 0.22$ \\
\hline $0.254 \pm 0.010$ & $3.67 \pm 0.25$ \\
\hline $0.349 \pm 0.010$ & $3.12 \pm 0.12$ \\
\hline $0.450 \pm 0.009$ & $3.11 \pm 0.33$ \\
\hline $0.662 \pm 0.034$ & $4.00 \pm 0.28$ \\
\hline $0.938 \pm 0.043$ & $3.79 \pm 0.18$ \\
\hline
\end{tabular}

Results are mean with s.e. $n=$ number of determinations. There was no significant difference $(P>0.05)$ between the clearance ratio at the highest and lowest plasma level of 3-OH PTMA. Analysis by Student's $t$-test and non-parametric test (Quenouille, 1959).

3-OH PTMA were determined. Six groups of clearance values were obtained for the following 3-OH PTMA plasma levels: $0.1-0.2, \quad 0.2-0.3$, $0.3-0.4,0.4-0.5,0.5-0.8$ and $0.8-1.1 \mu$ molar. The mean urine flow rate $\left(\mathrm{C}_{\text {In }}\right)$, plasma level of 3-OH PTMA and the 3-OH PTMA to inulin clearance ratio for each group are shown in Table 3. The clearance ratio was always greater than 1, confirming the previous report (Husain et al., 1969) that 3-OH PTMA is secreted by renal tubular mechanisms.

Six groups of clearance values were also obtained for the following plasma levels of the metabolites of 3-OH PTMA (hereafter called glucuronide), $0-0.1, \quad 0.1-0.2, \quad 0.2-0.3, \quad 0.3-0.4$, $0.4-0.5,0.5-0.8 \mu$ molar. The mean plasma level and the metabolite to inulin clearance ratio for each group are shown in Table 4 . The clearanc ratio was not statistically significantly different from 1 at plasma levels of $0.056-0.255 \mu$ molar glucuronide; however between plasma levels of 0.344-0.625 $\mu$ molar, the clearance ratio was significantly less than 1 (see Table 4). These results may suggest that the metabolites of 3-OH PTMA are eliminated by glomerular filtration and that a tubular reabsorptive component may be present. However, in the absence of plasma protein binding data, we cannot exclude the possibility of renal secretion of the glucuronide with progressive saturation (i.e. lower ratios) at higher plasma concentrations. Further experiments are necessary to elucidate these alternative possibilities.

\section{Pharmacokinetic studies}

\section{(a) Neostigmine}

After jugular vein administration. The fraction of the dose eliminated in urine as neostigmine and its total metabolites was the same for each dose administered over the time period studied following jugular vein administration. About 25\% of the dose was eliminated as neostigmine in $40 \mathrm{~min}$ and this increased to about $30 \%$ in 80 minutes. Less than $10 \%$ of the dose was eliminated as the metabolites of neostigmine in 80 minutes. These results are shown in Figure 1.

Table 4 The clearance ratio of the metabolites of $\left[{ }^{14} \mathrm{C}\right]$-3-hydroxyphenyltrimethylammonium iodide to inulin at various plasma concentrations

$\begin{array}{cccc}\text { Group } & \begin{array}{c}\text { Plasma conc. } \\ (\mu M)\end{array} & C_{\text {Metab. }} / C_{l n} & \mathrm{n} \\ 1 & 0.056 & 1.96^{*} & 16 \\ & \pm 0.007 & \pm 0.46 & \\ 2 & 0.153 & 1.08^{*} & 13 \\ & \pm 0.008 & \pm 0.04^{*} & \\ 3 & 0.255 & 1.06^{*} & 10 \\ & \pm 0.011 & \pm 0.05^{*} & \\ 4 & 0.344 & 0.75^{* *} & 9 \\ & \pm 0.007 & \pm 0.09^{*} & \\ 5 & 0.447 & 0.82^{* *} & 6 \\ & \pm 0.011 & \pm 0.06 & \\ 6 & 0.623 & 0.74^{* *} & 8 \\ & \pm 0.088 & \pm 0.04 & \end{array}$

Results are mean with s.e. $n=$ number of determinations. $P$ between group 1 and 2 and group 1 and $3=>0.05$; $P$ between group 1 and 4 , group 1 and 5 and group 1 and $6=<0.05$ (Quenouille, 1959; Student's $t$-test). Clearance ratio compared to $1={ }^{*} P>0.05,{ }^{*} * P<0.05$ (t-test). 


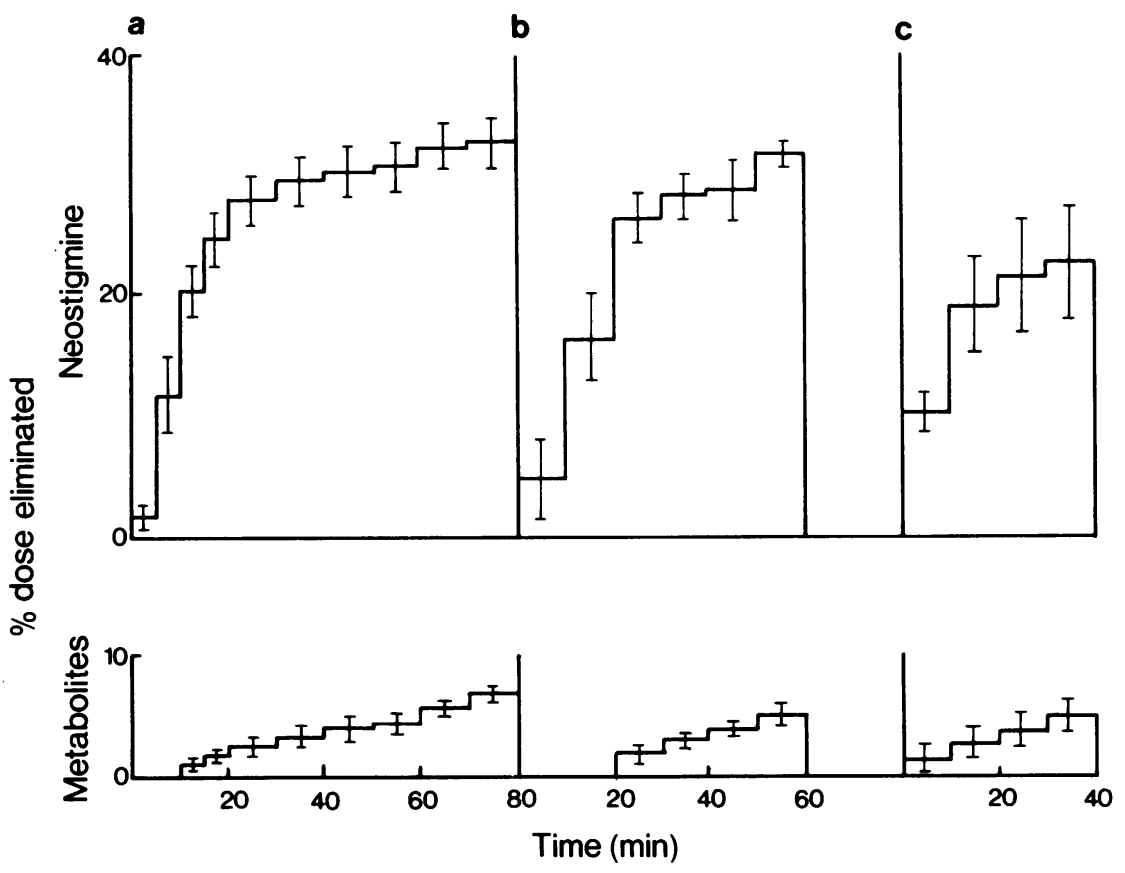

Fig. 1 Fraction of the dose eliminated in urine after jugular vein administration of neostigmine to rat. Results are mean with standard error. (a) $0.35 \mu \mathrm{mol} / \mathrm{kg}$; (b) $0.74 \mu \mathrm{mol} / \mathrm{kg}$; (c) $1.5 \mu \mathrm{mol} / \mathrm{kg}$.

The plasma concentration was determined only after administration of neostigmine $(0.74$ or $1.5 \mu \mathrm{mol} / \mathrm{kg}$ ). The plasma concentration fell very rapidly and the radioactive count rate was only $2-4$ times background $40 \mathrm{~min}$ after administration. When plotted semi-logarithmically with time the plasma curves could apparently be described by a bi-exponential function (see Figure 2). The half lives of each term of the exponential function are shown in Table 5.

The rate of excretion of neostigmine (percent fraction of the dose excreted per minute) was determined for each urine collection period following administration of $0.35 \mu \mathrm{mol} / \mathrm{kg}$ and was plotted semi-logarithmically with time at the mid-point of each urine collection period after allowing a delay time of $4 \mathrm{~min}$ between filtration at the glomerulus and appearance of the drug in the collecting vessel (Bourne \& Barber, 1972). The rate of excretion fell very rapidly initially and this was followed by a more slowly declining linear phase (see Figure 2). Each curve was analysed in terms of a bi-exponential function by the methods of residuals using a digital computer program. The fit chosen was that which minimized the logarithms of squared deviations between experimental and computed values (Mueller \& Lieberman, 1970). The half lives of each term of

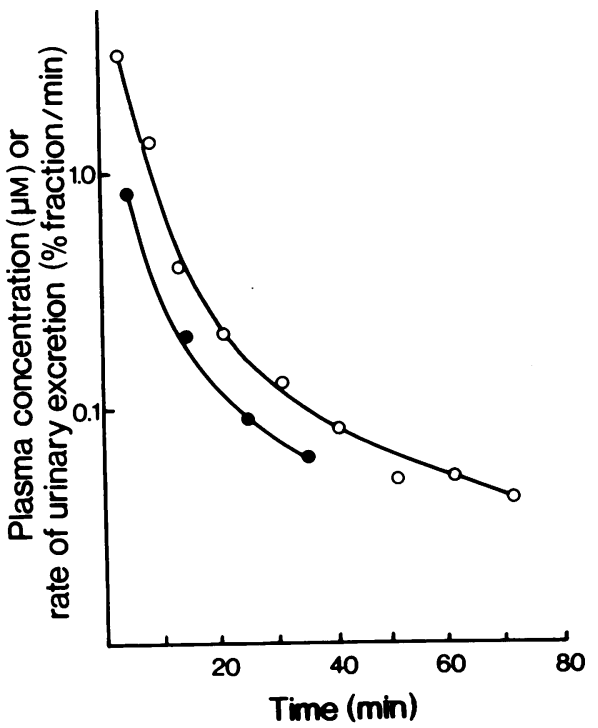

Fig. 2 An example of the plasma concentration-time curve and urinary excretion rate of $\left[{ }^{14} \mathrm{C}\right]$-neostigmine iodide after jugular vein administration in the rat. (๑) plasma concentration after $1.5 \mu \mathrm{mol} / \mathrm{kg}$; (o) urinary excretion rate after $0.35 \mu \mathrm{mol} / \mathrm{kg}$. 


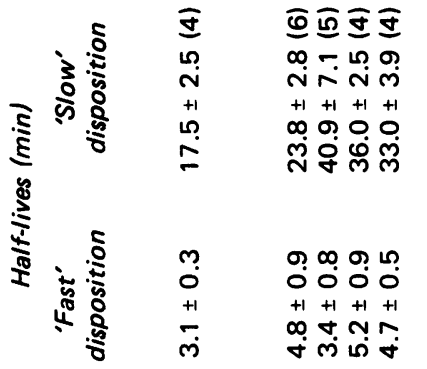

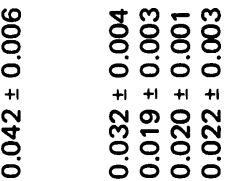

$\infty$

变

$0^{\infty} \overline{0} \overline{0}$ 000 $+1+1+1+1$

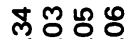
○ั0

ํํำำ ำ ํㅜㅇㅇํㅇ $+1+1+1+1$ 요 $\stackrel{0}{0}$ ㄷำ 0000

$<\frac{1}{8}$$$
\text { . }
$$

$\mathscr{0}=\dddot{m}: 0$ ○ं $0 \dot{0}$ $+1+1+1$ กำ ำ ำ लं० 00

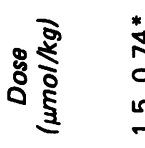

ํำ

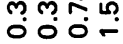

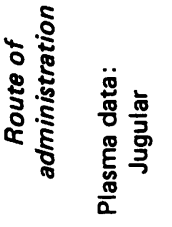

the function were similar to those determined from plasma data (see Table 5).

After portal vein administration. The fraction of the dose eliminated in urine as neostigmine was greatly reduced and the fraction eliminated as the metabolites greatly increased at each dose level when compared to jugular vein administration. Also following portal vein administration the fraction eliminated as neostigmine was dependent on the dose but the fraction eliminated as the metabolites did not change with dose over the time period studied. These results are shown in Figure 3.

Semi-logarithmic plots of urinary excretion rate of neostigmine with time, yielded apparent biexponential curves. Examples of such plots at the highest and lowest dose levels are shown in Figure 4. The half lives for each term of the bi-exponential function are shown in Table 5. When plotted semi-logarithmically with time the rate of excretion of the metabolites rose to a maximum at about $10 \mathrm{~min}$ and then declined in a bi-phasic manner (see Figure 4). During two experiments at the highest dose level administered by this route, the metabolite fraction was analysed for 3-OH PTMA and its glucuronide. No glucuronide was detected in urine until $30 \mathrm{~min}$ and only $1 \%$ of the dose was eliminated as the glucuronide in 80 minutes. The rate of excretion of the glucuronide was constant over the time period studied.

\section{(b) 3-Hydroxyphenyltrimethylammonium}

Jugular vein administration. After administration via the jugular vein (dose: $1.96 \mu \mathrm{mol} / \mathrm{kg}$ ) about $25 \%$ of the dose was eliminated in urine as 3-OH PTMA in $20 \mathrm{~min}$ and after $60 \mathrm{~min}$ almost $30 \%$ had been excreted by this route. Only $5 \%$ of the administered dose was eliminated as the metabolites in urine in $1 \mathrm{~h}$ (see Figure 5).

The plasma concentration of 3-OH PTMA determined during these experiments was plotted semi-logarithmically with time and analysed in terms of a bi-exponential function. Semilogarithmic plots of urinary excretion rate of 3-OH PTMA with time were also analysed in terms of a bi-exponential function and the half lives for each term of the function were similar to those determined from the plasma concentration time curves (see Table 6). An example of the changing plasma concentration and urinary excretion rate are shown in Figure 6.

Portal vein administration. The fraction of the dose eliminated unchanged in urine after portal vein administration of 3-OH PTMA was dependent on the dose. After a dose of $1.96 \mu \mathrm{mol} / \mathrm{kg}$, about $8 \%$ of the dose was eliminated in urine in 90 minutes. This was about 


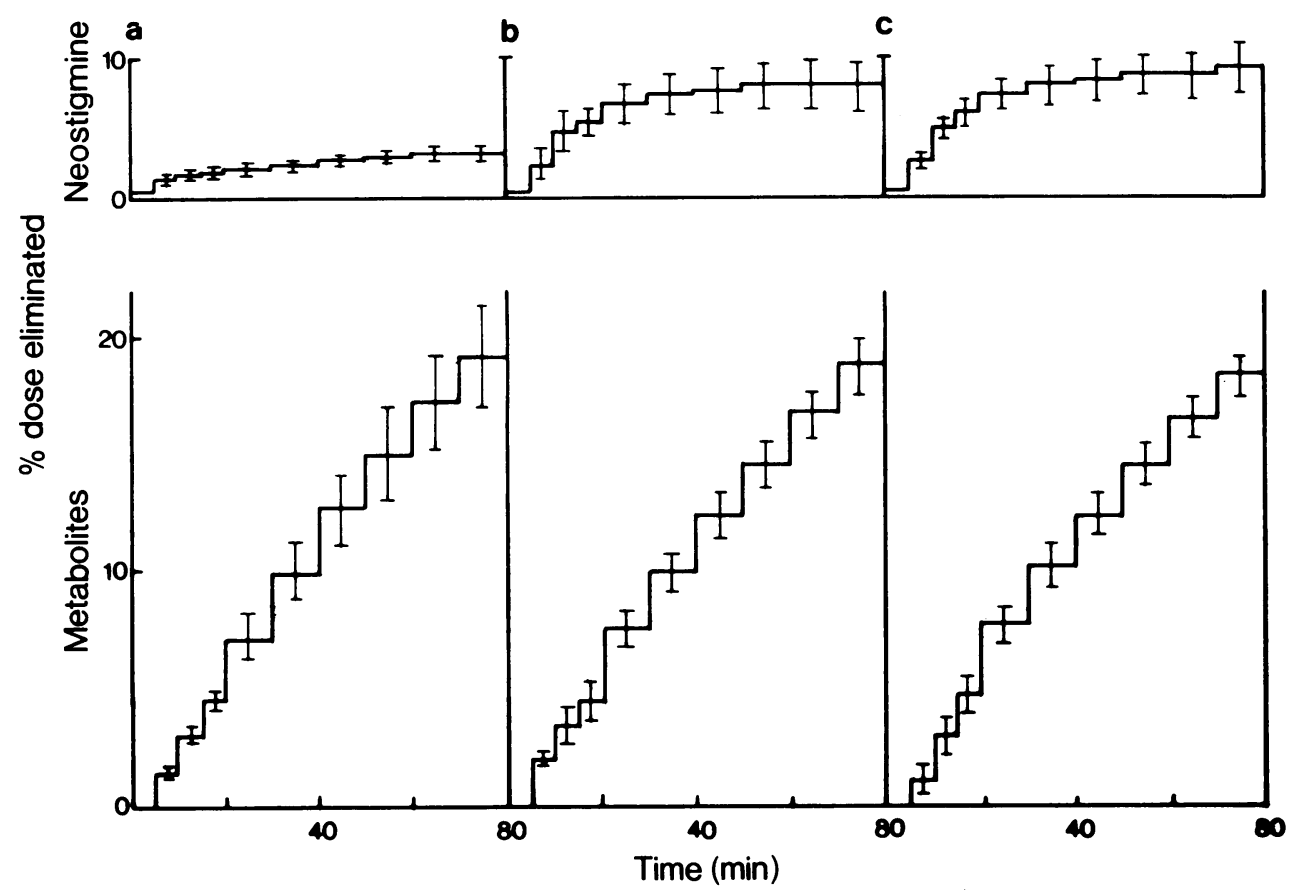

Fig. 3 Fraction of the dose excreted in urine after portal vein administration of neostigmine in rat. Results are mean with standard error. The fraction of neostigmine eliminated after the dose of $0.35 \mu \mathrm{mol} / \mathrm{kg}$ is significantly different $(P<0.05)$ from the fraction eliminated at the two higher doses, by Student's $t$ and the non-parametric test of Quenouille (1959). (a) $0.35 \mu \mathrm{mol} / \mathrm{kg}$; (b) $0.74 \mu \mathrm{mol} / \mathrm{kg}$; (c) $1.5 \mu \mathrm{mol} / \mathrm{kg}$.

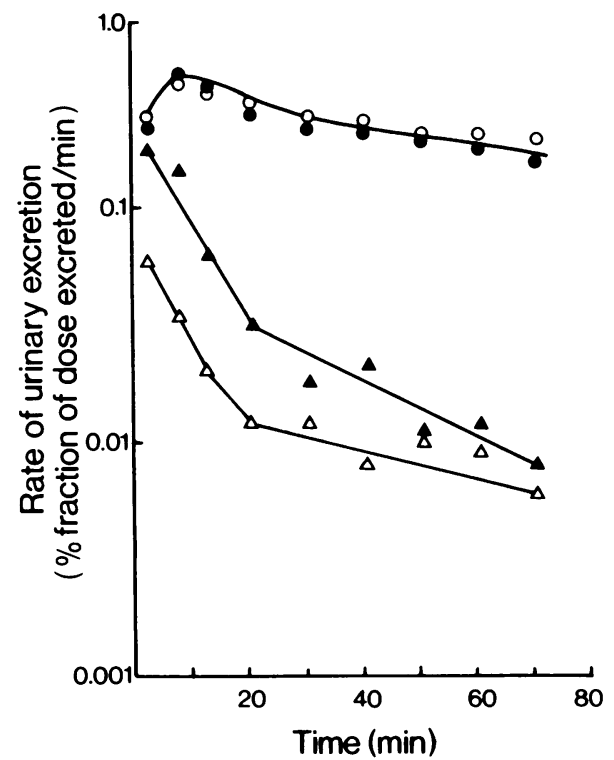

Fig. 4 An example of the rate of urinary excretion of neostigmine and its metabolites after portal vein administration of neostigmine. Dose $1.5 \mu \mathrm{mol} / \mathrm{kg}$ : (A) neostigmine; (๑) metabolites. Dose $0.35 \mu \mathrm{mol} / \mathrm{kg}:(\Delta)$ neostigmine; (0) metabolites. one-quarter of the fraction eliminated when the same dose was administered via the jugular vein. When the administered dose was reduced to $0.34 \mu \mathrm{mol} / \mathrm{kg}$, the fraction eliminated following portal vein administration was $3 \%$. Following portal vein administration, with increasing dose, the increase in the mean fraction of the dose eliminated as 3-OH PTMA was accompanied by a decrease in the mean fraction of the metabolites eliminated. These results are shown in Figure 5.

Semi-logarithmic plots of rate of excretion of 3-OH PTMA yielded a rapidly falling phase followed by a more slowly decreasing linear phase (see Figure 7). When analysed in terms of a bi-exponential function, the half lives of each term of the function were similar for each dose but the 'slow disposition' half life was increased when compared to that determined following jugular vein administration (see Table 6). Semi-logarithmic plots of the rate of excretion of the glucuronide rose during the first $30 \mathrm{~min}$ of each experiment but then the rate of excretion remaine 1 constant (see Figure 7).

In both the neostigmine and 3-OH PTMA investigations the experiments were of short duration and recovery of radioactivity in body fluids was not complete. However, because the 


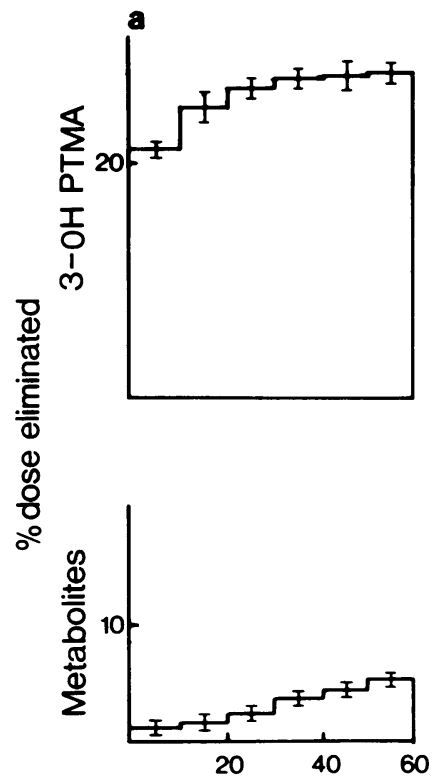

6
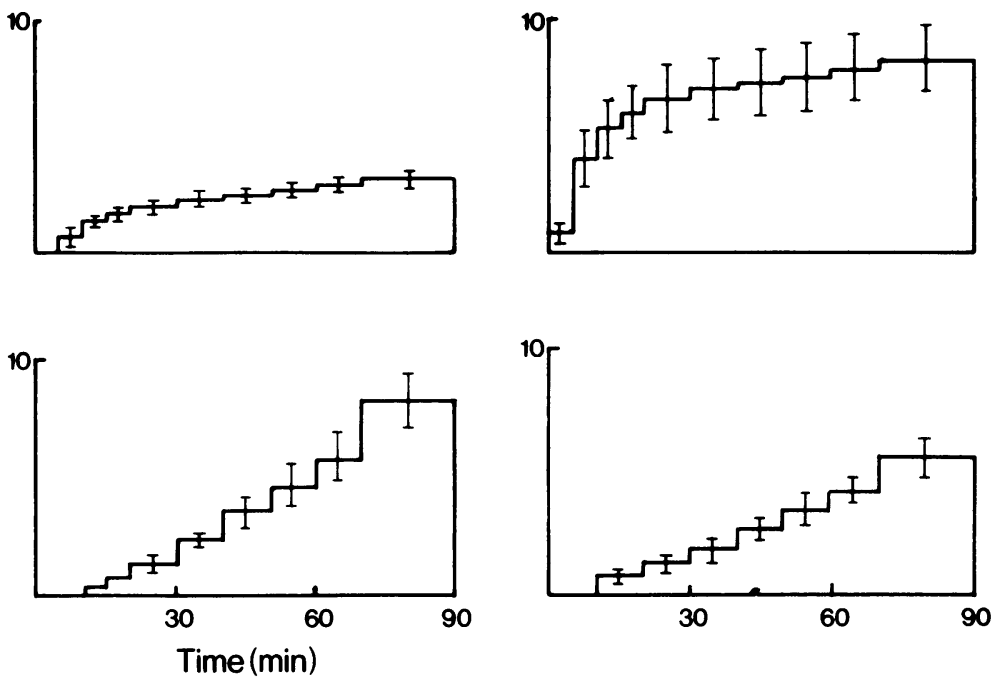

Fig. 5 Fraction of the dose eliminated in urine after administration of 3-hydroxyphenyltrimethylammonium iodide. Results are mean with standard error. (a) $1.96 \mu \mathrm{mol} / \mathrm{kg}$, via jugular vein; (b) $0.34 \mu \mathrm{mol} / \mathrm{kg}$, via portal vein; (c) $1.96 \mu \mathrm{mol} / \mathrm{kg}$, via portal vein.

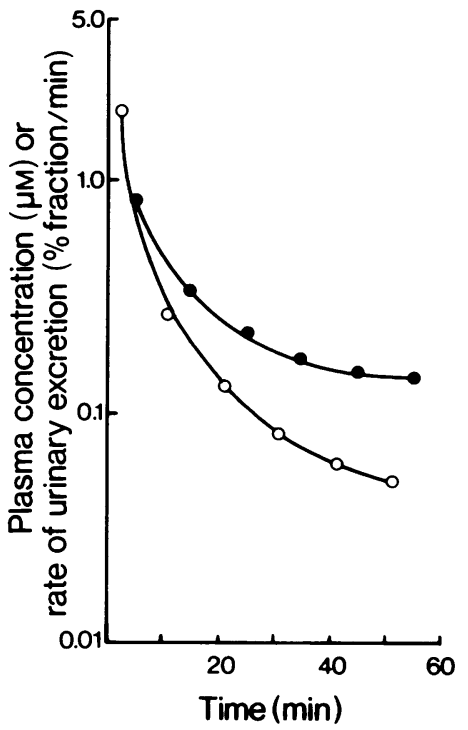

Fig. 6 An example of the plasma concentration-time curve $(\bullet)$ and urinary excretion rate $(0)$ of 3-hydroxyphenyltrimethylammonium iodide after jugular vein administration $(1.96 \mu \mathrm{mol} / \mathrm{kg})$.

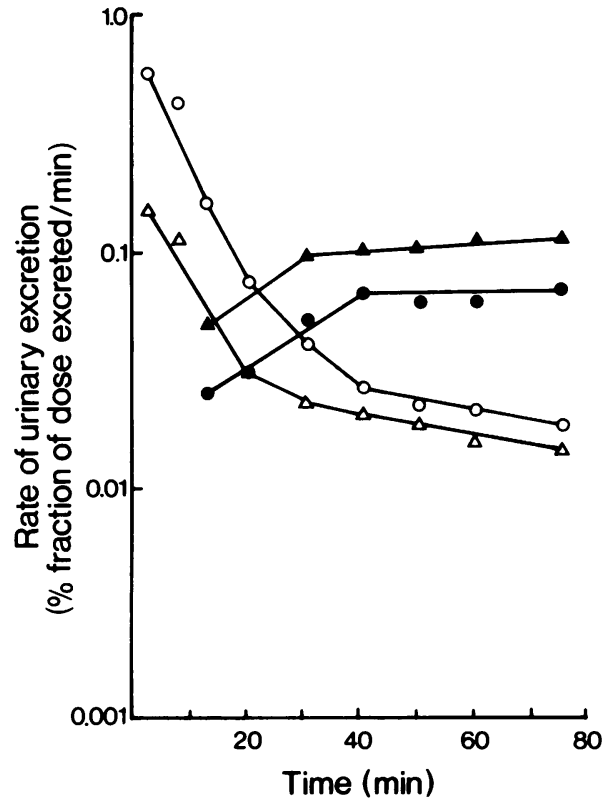

Fig. 7 An example of the rate of urinary excretion of 3-hydroxyphenyltrimethylammonium iodide (3-OH PTMA) and its glucuronide after portal vein administration of 3-OH PTMA. Dose $1.96 \mu \mathrm{mol} / \mathrm{kg}$ : (o) 3-OH PTMA, (०) glucuronide. Dose $0.34 \mu \mathrm{mol} / \mathrm{kg}$ :

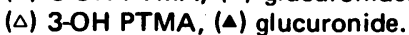


fraction excreted as parent drug in all experiments approached an asymptote (see Figs 1, 3 and 5), it is considered that the data collected over 60-90 min are a good reflection of the fate of these molecules.

\section{Discussion}

Comparison of the clearance of neostigmine and 3-OH PTMA with that of inulin confirmed that both compounds are eliminated by renal tubular secretion as previously described (Roberts et al., 1965a; Husain et al., 1969). Since the clearance ratio of these compounds compared to inulin was independent of the plasma level they are eliminated by dose-independent processes and the capacity of the transport pathway was not exceeded over the plasma range studied. Studies on the renal clearance of the metabolites of 3-OH PTMA have not previously been described. No comparison of these clearance results was made with those calculable from the pharmacokinetic studies after rapid intravenous injection. In this latter case, it is very difficult to assess the correct plasma concentration responsible for the rate of excretion of a compound intis the urine. This is most marked for clearances calculated for periods shortly after injection of the drug. The plasma concentration is changing rapidly and erroneously high clearance values can be calculated.

After the administration of different doses of neostigmine by rapid intravenous injection via the jugular vein, no change in the fractional composition of excretion products with dose was observed, but over the same dose range changes in fractional composition of excretion products with dose were observed following portal vein administration, suggesting dose-dependent elimination kinetics. The possibility of observing, over a given dose range, non-linear pharmacokinetics with one route of administration but not with another has recently been reported for data simulated by computer (Gibaldi \& Feld man, 1972).

Following portal vein administration of neostigmine, the capacity of the metabolic pathway, neostigmine to 3-OH PTMA, is apparently not exceeded over the range of dose levels studied. Saturation of this pathway would result in increased neostigmine and decreased 3-OH PTMA fractions eliminated as the dose of neostigmine was increased (Levy, 1968). No effect on the fractions of 3-OH PTMA was noted. Since a smaller fraction of neostigmine was excreted at the lowest dose studied, it is possible that at the higher doses a low capacity reabsorptive site for neostigmine is exceeded, allowing more to be excreted. This may explain the dose dependency 
observed. Studies on the renal clearance of neostigmine did not exclude this possibility as the plasma levels were too low for clearances to be measured after portal administration. Limited reabsorptive components for polar organic compounds have been reported (Cho \& Cafruny, $1970)$. The fraction of the dose eliminated as neostigmine was greatly reduced and the metabolite fraction increased after portal vein administration of a given dose, compared to jugular vein administration of the same dose; thus this compound is subject to extensive metabolism during the first passage through the liver. Dosedependent effects after portal vein administration and the apparent first passage phenomena were also observed for 3-OH PTMA. The dosedependence of 3-OH PTMA was apparently due to saturation of the metabolic pathway of this compound. Saturation of the metabolic pathway results in an increase in the fraction eliminated as parent drug and decrease in the metabolite fraction with increasing dose and a constant rate of urinary excretion of the metabolite (Levy, 1968). These parameters were observed with 3-OH PTMA.

A comparison of the results after the administration of equimolar doses of neostigmine and 3-OH PTMA via the portal vein is instructive. Following portal vein administration of neostigmine $(0.35 \mu \mathrm{mol} / \mathrm{kg})$ almost $20 \%$ of the dose was eliminated in urine as the metabolites and $2 \%$ as neostigmine. However, when 3-OH PTMA was administered at an almost equimolar dose level $(0.34 \mu \mathrm{mol} / \mathrm{kg})$ only $3 \%$ of the dose was eliminated in urine as 3-OH PTMA and less than $10 \%$ as its metabolites over the same time period. When the dose of 3-OH PTMA was increased 6-fold the fraction excreted unchanged only increased to $8 \%$. Since studies on the renal clearance of 3-OH PTMA showed that it is rapidly cleared from the plasma, it is expected that after portal vein administration 3-OH PTMA would be very rapidly excreted in the urine. Variations in the fraction of 3-OH PTMA eliminated after administration of neostigmine or 3-OH PTMA may be due to tissue binding of these compounds, perhaps in hepatic tissue. If neostigmine has more affinity for the proposed binding sites than its

\section{References}

BARBER, H.E. \& BOURNE, G.R. (1973). Scintillation counting: channels ratio and external standard channels ratio for the determination of counting efficiency in Triton X-100 based scintillants. Br. $J$. Pharmac., 48, 366-367P.

BARBER, H.E., BOURNE, G.R. \& BUCKLEY, G.A. metabolites, then 3-OH PTMA formed by metabolism from neostigmine will be rapidly excreted as observed; in the absence of neostigmine, 3-OH PTMA may be bound to these sites and be less completely eliminated. Non-linear distribution phenomena due to tissue binding have been described recently for highly polar drugs (DiSanto \& Wagner, 1972) and this phenomenon may also explain the non-linear elimination of neostigmine.

The 'biological half lives' of neostigmine and 3-OH PTMA were determined from semilogarithmic plots of plasma concentration or urinary excretion rate with time, but the change in these parameters was probably not truly exponential, since the drugs are eliminated by non-linear kinetics (Levy, 1968). Variations in half life with route of administration determined from urinary excretion data for neostigmine may be due to the non-exponential decline in drug levels. However, the more pronounced difference in 'biological half life' with different routes of administration for 3-OH PTMA are probably due to difference in the time period over which samples were collected (Gibaldi \& Weintraub, 1971).

For drugs which are eliminated by first order kinetics after repeated dosing, the drug attains a plateau level, which is proportional to the dose administered, but when drugs are eliminated by non-linear kinetics the magnitude of the plateau is not directly proportional to the dose but may change in a manner other than proportionately (Tsuchiya \& Levy, 1972). The results presented here indicate that neostigmine is eliminated by non-linear mechanisms after portal vein administration (which is equivalent to the route used for therapy). These studies have indicated the necessity to determine the pharmacokinetics of a drug after administration via the route used for therapy and to determine if the elimination kinetics are dose-dependent by the administration of several doses.

We would like to thank Professor A. Wilson for his advice in the writing of this manuscript and Dr T.N. Calvey for helpful comments and suggestions.
(1972). The use of liquid cation exchange in the extraction and separation of ${ }^{14} \mathrm{C}$ neostigmine iodide and its metabolite ${ }^{14} \mathrm{C}$ 3-hydroxyphenyltrimethylammonium iodide from body fluids. J. Pharm. Pharmac., 24, 907-908.

BOURNE, G.R. \& BARBER, H.E. (1972). The pharmaco- 
kinetics of inulin and urea: a comparison of the dose eliminated from a compartmental model and that eliminated in urine. J. Pharm. Pharmac., 24, 532-537.

CALVEY, T.N. (1966). The biliary excretion of neostigmine in the rat. Br. J. Pharmac. Chemother., 28, 348-359.

CHO, K.C. \& CAFRUNY, E.J. (1970). Renal tubular reabsorption of p-amino-hippuric acid (P.A.H.) in the dog. J. Pharmac. exp. Ther., 173, 1-12.

DISANTO, A.R. \& WAGNER, J.G. (1972). Pharmacokinetics of highly ionised drugs III: Methylene blueblood levels in the dog and tissue levels in the rat following intravenous administration. J. Pharm. Sci., 61, 1090-1094.

GIBALDI, M. \& FELDMAN, S. (1972). Route of administration and drug metabolism. Eur. J. Pharmac., 19, 323-329.

GIBALDI, M. \& WEINTRAUB, H. (1971). Some considerations as to the determination and significance of biologic half-life. J. Pharm. Sci., 60, 624-626.

HUSAIN, M.A., ROBERTS, J.B., THOMAS, B.H. \& WILSON, A. (1969). Metabolism and excretion of 3-hydroxyphenyltrimethylammonium and neostigmine. Br. J. Pharmac., 35, 344-350.

LEVY, G. (1968). Dose dependent effects in pharmacokinetics. In Importance of fundamental principles in Drug Evaluation, pp. 141-172. ed. Tedeschi, D.H. \& Tedeschi, R.E. New York, N.Y.: Raven Press.

MUELLER, F.W. \& LIEBERMAN, S.V. (1970). Fitting a double exponential curve to observed salicylate concentrations in blood. J. Pharm. Sci., 59, 514-517. QUENOUILLE, M.N. (1959). Test of the difference in mean level between two groups of observations. In Rapid statistical calculations, p. 14. London: Charles Griffen \& Co., Ltd.

ROBERTS, J.B., THOMAS, B.H. \& WILSON, A. (1965a). Distribution and excretion of ${ }^{14} \mathrm{C}$ neostigmine in the rat and hen. Br. J. Pharmac. Chemother., 25, 234-242.

ROBERTS, J.B., THOMAS, B.H. \& WILSON, A. (1965b). Metabolism of ${ }^{14} \mathrm{C}$ neostigmine in the rat. $\mathrm{Br} . J$. Pharmac. Chemother., 25, 763-770.

SMITH, H. (1956). Principles of renal physiology. Chapters 6-8. New York: Oxford University Press.

SOMANI, S.M., ROBERTS, J.B., THOMAS, B.H. \& WILSON, A. (1970). Isolation and characterisation of metabolites of neostigmine from rat urine. Eur. J. Pharmac., 12, 114-119.

SOMANI, S.M., WRIGHT, A. \& CALVEY, T.N. (1970). The biliary excretion of trimethyl- ${ }^{14} \mathrm{C}(3-\mathrm{hyd}$ droxyphenyl)ammonium iodide and its metabolic products. Eur. J. Pharmac., 12, 109-113.

TSUCHIYA, T. \& LEVY, G. (1972). Relationship between dose and plateau levels of drugs eliminated by parallel first order and capacity limited kinetics. $J$. Pharm. Sci., 61, 541-544. 